\title{
Separation and Determination of Trace Dinitropyrenes by Means of Off-Line Reduction-HPLC-Chemiluminescence Detection. Application to Assessing Atmospheric Environment
}

\author{
Mizuo Maeda*, Kazuhiko Tsukagoshi*, Masaharu Murata*, \\ Makoto TAKAGI* and Toshiro YAMASHITA** \\ * Department of Chemical Science and Technology, Faculty of Engineering, Kyushu University, \\ Hakozaki, Higashi, Fukuoka 812, Japan \\ **The Kitakyushu Municipal Institute of Environmental Health Sciences, \\ Shin-ike, Tobata, Kitakyushu 804, Japan
}

\begin{abstract}
A flow injection analysis (FIA) system using a bis(2,4,6-trichlorophenyl)oxalate (TCPO)-hydrogen peroxide $\left(\mathrm{H}_{2} \mathrm{O}_{2}\right)$ chemiluminescence (CL) system was developed for the determination of small amounts of polycyclic aromatic hydrocarbons (PAHs). The system allowed us to determine PAH over a wide range of concentrations with the detection limits $(S / N=5)$ of $0.05 \mathrm{pg}$ (perylene), $65 \mathrm{pg}$ (anthracene), and $75 \mathrm{pg}$ (pyrene). On the basis of the results, an off-line reduction-HPLC-CL detection system was developed for separation and determination of dinitropyrenes (DNPs) as the specific PAH. DNPs were reduced to diaminopyrenes (DAPs), which were then analyzed by the HPLC equipped with the $\mathrm{CL}$ detector. A metal-free system was developed by use of plastic-frame column and all Teflon-made line. These new devices have improved the sensitivity and the reproducibility of determination; DNPs were determined over a wide range of concentration with the detection limit $(S / N=5)$ of $0.025 \mathrm{pg}(1,8-, 1,6-\mathrm{DNP})$ and $0.05 \mathrm{pg}(1,3-\mathrm{DNP})$. The present off-line reduction-HPLC system was applied to the determination of individual DNP at trace levels in the atmosphere.
\end{abstract}

Keywords Chemiluminescence, flow injection analysis, high performance liquid chromatography, dinitropyrene, environmental analysis

The potent mutagenic activity of polycyclic aromatic hydrocarbons (PAHs) has been the focus of serious attention in recent years. ${ }^{1,2}$ Methods for the determination of trace amounts of PAH have been strongly demanded. Chemiluminescence (CL) and fluorescence methods are very sensitive compared with other analytical methods. Recently, CL detection using a bis(2,4,6-trichlorophenyl)oxalate (TCPO)-hydrogen peroxide $\left(\mathrm{H}_{2} \mathrm{O}_{2}\right)$ system was employed as a highly sensitive detection method for PAHs ${ }^{3-6}$ in some cases, their detection limits were much better than those obtained by fluorescence. However, the CL detection has not been applied in practice to the determination of PAH in environmental samples.

It is necessary for the environmental analysis to determine the specific PAH individually with the aid of an appropriate chromatographic method for separation. However, a highly-sensitive and -reproducible detection system is a key for the trace-analyses. Therefore, in the present study, a flow injection analysis (FIA) using the TCPO- $\mathrm{H}_{2} \mathrm{O}_{2} \mathrm{CL}$ system was studied in detail in order to improve the detection system for a small amount of PAH. On the basis of the results, an off-line reductionHPLC-CL detection using the TCPO- $\mathrm{H}_{2} \mathrm{O}_{2}$ system was developed for the separation and determination of dinitropyrenes (DNPs), which are known as the most mutagenic species among PAHs and their derivatives. ${ }^{1,7}$ By optimizing the analytical conditions, as well as by introducing new techniques such as metal-free devices, a small amount of diaminopyrenes (DAPs), which were obtained by reduction of DNP isomers, was determined with good sensitivity and reproducibility. DNPs in the atmospheric environment were successfully determined by use of the present off-line reduction-HPLC-CL detection system.

\section{Experimental}

\section{Reagents}

TCPO (Tokyo Kasei Kogyo Co., Ltd.); $\mathrm{H}_{2} \mathrm{O}_{2}$, pyrene (Wako Pure Chemical Industries, Ltd.); anthracene, perylene (Kishida Chemical Co., Ltd.); 1,6-, 1,8-, and 1,3DNP (Aldrich) and acetonitrile $\left(\mathrm{CH}_{3} \mathrm{CN}\right)$ (Kanto Chemical Co., Inc.; for HPLC) were used as received. Other reagents used were commercially available special grade. Water was purified by means of a Milli-Q Reagent Water System (Nippon Millipore Ltd.) before use. 


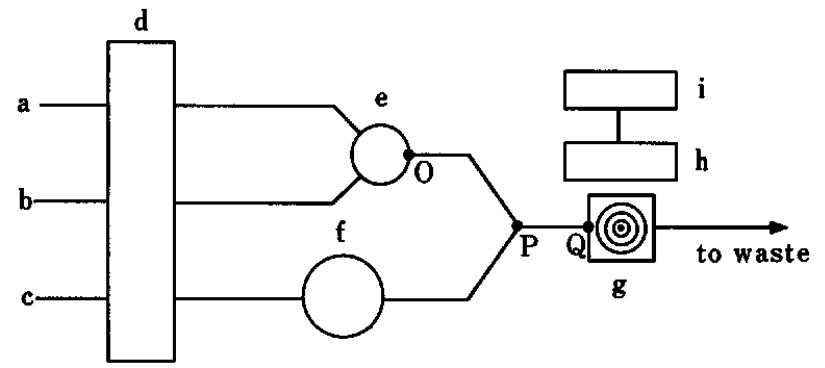

Fig. 1 Schematic diagram of FIA system. a: $\mathrm{TCPO} / \mathrm{CH}_{3} \mathrm{CN}$ solution, b: $\mathrm{H}_{2} \mathrm{O}_{2} / \mathrm{CH}_{3} \mathrm{CN}$ solution, c: carrier $\left(\mathrm{CH}_{3} \mathrm{CN}\right)$ solution, d: pumps, e: dynamic mixer, f: sample injector, $\mathrm{g}$ : flow cell, h: CL detector, and i: integrator.

\section{Apparatus and procedure}

FIA system. The schematic diagram of FIA is shown in Fig. 1. A Teflon tube $(1.0 \mathrm{~mm}$ i.d. except for the $0.8 \mathrm{~mm}$ i.d. from $\mathrm{P}$ to $\mathrm{Q}$ ) and a connector were used. A $0.5 \mathrm{mmol} \mathrm{dm}^{-3} \mathrm{TCPO} / \mathrm{CH}_{3} \mathrm{CN}$ solution (a) and a $0.9 \mathrm{~mol} \mathrm{dm}^{-3} \mathrm{H}_{2} \mathrm{O}_{2} / \mathrm{CH}_{3} \mathrm{CN}$ solution (b) were delivered at the flow rate of $0.5 \mathrm{~cm}^{3} \mathrm{~min}^{-1}$, and a $\mathrm{CH}_{3} \mathrm{CN}$ carrier solution (c) was delivered at $1.0 \mathrm{~cm}^{3} \mathrm{~min}^{-1}$ with the corresponding pumps. Solutions (a) and (b) were first mixed; then the resulting mixture was combined with (c); the distances between $P$ and $O$ and beween $P$ and $Q$ were 20 and $10 \mathrm{~cm}$, respectively. A definite amount $(37 \mu \mathrm{l})$ of sample solution containing a certain $\mathrm{PAH}$, which was dissolved in $\mathrm{CH}_{3} \mathrm{CN}$, was injected into the line (c). The CL intensity of the solution was measured by a CL detector (TOA; ICA-3070).

HPLC system. The HPLC-CL detection system was developed on the basis of the FIA. The system illustrated in Fig. 1 was modified by inserting a separation column between $f$ and $P$ on the line of carrier solution of FIA system. The sample injection volume was $20 \mu \mathrm{l}$. The column used was 4.6 i.d. $\times 250 \mathrm{~mm}$ ODS (GL Science). For the analysis of DAP, the carrier solution was $\mathrm{CH}_{3} \mathrm{CN}$-aqueous imidazole $\left(10 \mathrm{mmol} \mathrm{dm}^{-3}\right.$, pH 7.5) $(1: 1)$ and the concentration of $\mathrm{H}_{2} \mathrm{O}_{2}$ in $\mathrm{H}_{2} \mathrm{O}_{2} /$ $\mathrm{CH}_{3} \mathrm{CN}$ was $0.2 \mathrm{~mol} \mathrm{dm}^{-3}$. A metal-free system was introduced by use of plastic-frame column and all Teflonmade line.

Collection and reduction of DNP for HPLC. Suspended particulate matter in air was collected on a glassfiber filter $(203 \mathrm{~mm} \times 254 \mathrm{~mm})$ by a high-volume air sampler (KIMOTO; $121 \mathrm{~F}$ type) for $12 \mathrm{~h}$ at the flow rate of $1.1 \mathrm{~m}^{3} \mathrm{~min}^{-1}$. A $1 / 8$ portion of the filter was extracted with $30 \mathrm{~cm}^{3}$ of dichloromethane by sonication for $15 \mathrm{~min}$. The supernatant solution was filtered; then the filtrate was concentrated to $1-2 \mathrm{~cm}^{3}$ by evaporation, followed by drying under a nitrogen stream. The residue was dissolved in $1 \mathrm{~cm}^{3}$ of hexane, and the whole hexane solution was subjected to Sep-Pak ${ }^{\circledR}$ silica cartrige (Waters Associates). After successive elutions by $45 \mathrm{~cm}^{3}$ of hexane and $10 \mathrm{~cm}^{3}$ of diethyl ether-hexane (1:99), a fraction eluted by $12 \mathrm{~cm}^{3}$ of hexanedichloromethane $(1: 1)$ was collected. The fraction comprises DNPs. ${ }^{8}$ The fraction was concentrated to $c a .1 \mathrm{~cm}^{3}$ by using a rotary evaporator, and then was dried under a nitrogen stream. The residue was dissolved in $1 \mathrm{~cm}^{3}$ of ethanol.

One cubic centimeter of $7 \mathrm{wt} \%$ sodium hydrogensulfide was added to the DNP-containing ethanol solution for the reduction to DAP. 9 The solution was left for $24 \mathrm{~h}$ at room temperature. To the solution, $1 \mathrm{~cm}^{3}$ of benzene and $4 \mathrm{~cm}^{3}$ of $0.15 \mathrm{~mol} \mathrm{dm}^{-3}$ sodium hydroxide were added; then the solution was shaken for $15 \mathrm{~min}$. The benzene phase was used as a DAP sample solution for HPLC-CL detection. In all experiments, the DAP solution was treated with care to avoid exposure to light. An ethanol solution of DNP as a standard sample was treated in a similar manner.

\section{Results and Discussion}

\section{FIA system}

The optimum conditions for FIA were determined with regard to reagent concentration, kind of organic solvent, sample volume, flow rate, reaction time, tube diameter, mixing procedure, mixing order, and so on. The CL profile and the calibration curves obtained under the optimum conditions are shown in Figs. 2 and 3, respectively, in which perylene, anthracene, and pyrene were used as model PAH. Each PAH showed a different sensitivity for CL. The plot of CL intensity against oxidation potential of $\mathrm{PAH}^{10}$ gave a good relationship (Fig. 4). This indicates that the reaction in TCPO- $\mathrm{H}_{2} \mathrm{O}_{2}-\mathrm{PAH} \mathrm{CL}$ system proceeds through the charge-transfer transition state. ${ }^{11}$

Dynamic range, detection limit, relative standard deviation, and sampling rate for the present system are summarized in Table 1. Other workers reported the following detection limits: ${ }^{3} 0.77 \mathrm{pg}$ (perylene), $130 \mathrm{pg}$

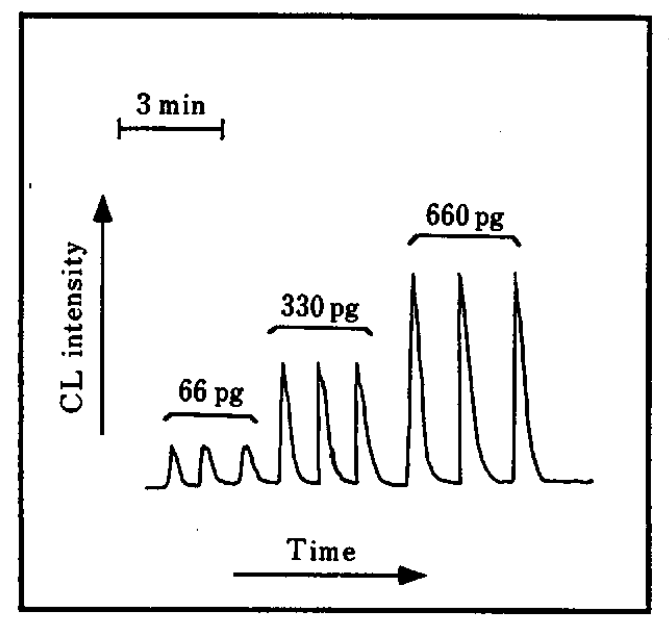

Fig. 2 CL profile for anthracene by FIA system. Conditions: $\mathrm{TCPO} / \mathrm{CH}_{3} \mathrm{CN}, \quad 0.5 \mathrm{mmol} \mathrm{dm}^{-3} ; \mathrm{H}_{2} \mathrm{O}_{2} / \mathrm{CH}_{3} \mathrm{CN}$, $0.9 \mathrm{~mol} \mathrm{dm}^{-3}$. 


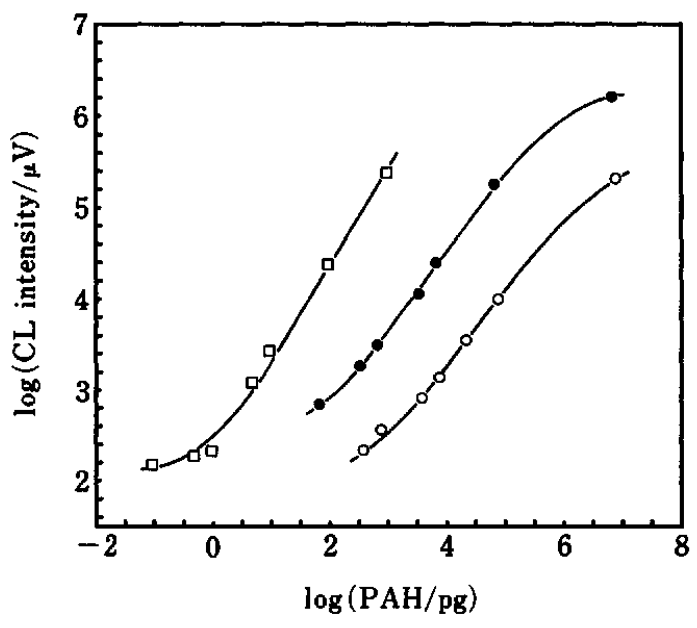

Fig. 3 Calibration curves for PAHs by FIA system. $\square$ : perylene, 0 : anthracene and $\mathrm{O}:$ pyrene. Conditions: TCPO/ $\mathrm{CH}_{3} \mathrm{CN}, 0.5 \mathrm{mmol} \mathrm{dm}^{-3} ; \mathrm{H}_{2} \mathrm{O}_{2} / \mathrm{CH}_{3} \mathrm{CN}, 0.9 \mathrm{~mol} \mathrm{dm}^{-3}$.

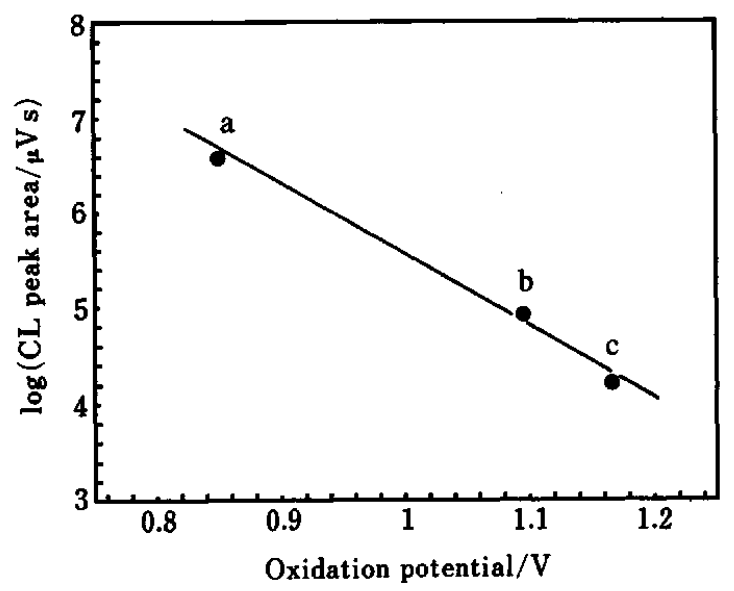

Fig. 4 The plot of $C L$ peak areas against oxidation potentials. a: perylene, b: anthracene, and c: pyrene. Each CL peak area was measured for a $200 \mathrm{pg}$ PAH sample.

(anthracene), $7300 \mathrm{pg}$ (pyrene) in $\mathrm{TCPO}-\mathrm{H}_{2} \mathrm{O}_{2}$ detection system and $80 \mathrm{pg}$ (perylene), $1000 \mathrm{pg}$ (anthracene), $240 \mathrm{pg}$ (pyrene) in fluorescence system. In comparison with these values, the present FIA system may be characterized by high-sensitivity as well as easy operation and rapid measurement.

\section{Development of HPLC system}

The trace determination of the specific PAH will be attained by a combination of the sensitive detection system and an appropriate chromatographic method for separation. In the present study, DNPs were adopted as the target PAH because DNPs are known as the most mutagenic species among PAHs. ${ }^{1,7}$

Since DNPs are substantially nonfluorescent due to an effective quenching by the nitro group(s), they were reduced to the DAPs according to the procedure described in the experimental section.

An HPLC system equipped with the CL detector was developed for the analysis of DAPs on the basis of the FIA study. The conditions for the elution were examined, and an eluent from $\mathrm{CH}_{3} \mathrm{CN}$-aqueous solution of imidazole $\left(10 \mathrm{mmol} \mathrm{dm}^{-3} \mathrm{pH} 7.5\right)(1: 1)$ was finally chosen.

\section{Metal-free HPLC system}

Although the reduction of DNP to DAP allowed detection by the CL system, the DAPs are very unstable and easily converted to hydroxylamino compounds or nitroso compounds by being exposed to light or coming into contact with metal ${ }^{6}$, resulting in diminished CL intensity. In order to determine the effect of metal, the DAP solutions were passed through stainless-steel and Teflon tubings and the CL intensities were measured by the FIA system. Four meters of stainless-steel tubing reduced the $\mathrm{CL}$ intensity to be about $60 \%$ of that obtained by using the same length of Teflon tubing. Therefore, in the present study, metal-free system was developed by use of plastic-frame column and all Teflonmade line. Furthermore, a syringe having a platinum needle was employed when a DAP sample was injected into the system.

The chromatograms obtained for DNP mixture (1,6-, 1,8-, and 1,3-) by the HPLC-CL system before improvement (System A), by the system improved by using ascorbic acid as antioxidant (System B), and by the metal-free system (System C) are shown in Fig. 5. The use of ascorbic acid has been proposed for the improvement of CL stability by Hayakawa et al. ${ }^{6}$ System A showed a small CL intensity without any peak separation. Although System B has much improved the intensity and has achieved resolution of three peaks, a negative peak due to ascorbic acid was observed, resulting in distortion of the baseline. System $\mathrm{C}$ gave a well-defined chromatogram.

Table 1 Analytical capabilities of the present FIA system for PAHs

\begin{tabular}{|c|c|c|c|c|c|c|c|c|}
\hline \multirow[b]{2}{*}{ PAH } & \multirow{2}{*}{$\begin{array}{c}\text { Determinable } \\
\text { range } / \mathrm{mol} \mathrm{dm}^{-3}\end{array}$} & \multirow{2}{*}{$\begin{array}{l}\text { Detection } \\
\text { limit/pg } \\
(S / N=5)\end{array}$} & \multicolumn{3}{|c|}{ Relative standard deviation $(n=8), \%$} & \multicolumn{3}{|c|}{ Sampling rate (samples/h) } \\
\hline & & & $1 \times 10^{-3} \mathrm{~mol} \mathrm{dm}^{-3}$ & $1 \times 10^{-7}$ & $1 \times 10^{-11}$ & $1 \times 10^{-3} \mathrm{~mol} \mathrm{dm}^{-3}$ & $1 \times 10^{-5}$ & $1 \times 10^{-8}$ \\
\hline Perylene & $10^{-11}-10^{-7}$ & 0.05 & - & 2.9 & 6.0 & & & \\
\hline Anthracene & $10^{-8}-10^{-3}$ & 65 & 0.06 & 3.1 & - & 100 & 75 & 60 \\
\hline Pyrene & $10^{-8}-10^{-3}$ & 75 & 0.9 & 7.0 & - & & & \\
\hline
\end{tabular}




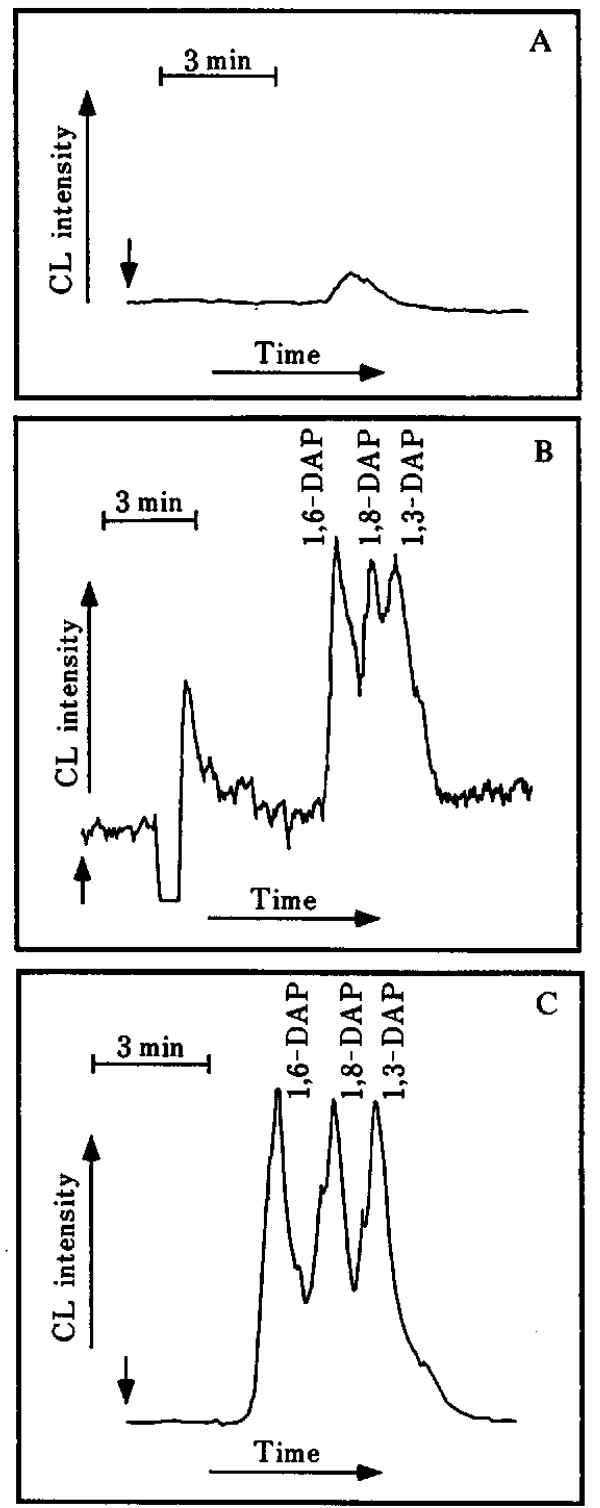

Fig. 5 Chromatograms of DAPs obtained by off-line reduction-HPLC-CL systems. System A: the system before improvement; System B: the system improved by using ascorbic acid (10 $\mathrm{mmol} \mathrm{dm}^{-3}$ in sample); and System C: the present metal-free system. Conditions: $\mathrm{TCPO} / \mathrm{CH}_{3} \mathrm{CN}$, $0.5 \mathrm{mmol} \mathrm{dm}^{-3} ; \quad \mathrm{H}_{2} \mathrm{O}_{2} / \mathrm{CH}_{3} \mathrm{CN}, \quad 0.2 \mathrm{~mol} \mathrm{dm}^{-3}$; eluent, $\mathrm{CH}_{3} \mathrm{CN}$-aqueous imidazole $\left(10 \mathrm{mmol} \mathrm{dm}^{-3}, \mathrm{pH} 7.5\right)(1: 1)$; sample, mixture containing 1,6-, 1,8-, and 1,3-DNP (100 pg each); column, 4.6 i.d. $\times 250 \mathrm{~mm}$ ODS.

\section{Separation and determination of DNPS by HPLC}

Figure 6 shows the calibration curve for DNPs. The straight line with slope close to unity was quite reproducible for 5 different runs within this concentration range. The present off-line reductionHPLC-CL detection system made it possible to determine DNP over a wide range of concentration with the detection limits $(S / N=5)$ of $0.025 \mathrm{pg}(1,8-, 1,6-\mathrm{DNP})$ and $0.05 \mathrm{pg}(1,3-\mathrm{DNP})$. Table 2 shows the detection limit of the present method, together with those of the conventional methods such as fluorescence ${ }^{9}$ and $\mathrm{CL}$ methods. ${ }^{6}$ The present method thus improved substantially the sensitivity for the determination of DNP.

Application of HPLC system to atmospheric environment

The present HPLC system was applied for the first time to the determination of DNPs in the atmosphere. The analytical samples were collected by a high-volume air sampler (a dust collector) in a shopping mall in an urban area of Fukuoka in winter, 1992. The chromatographic data led to the concentrations of $9.5 \mathrm{pg} \mathrm{m}^{-3}$ (1,6-DNP), $7.5 \mathrm{pg} \mathrm{m}^{-3}$ (1,8-DNP), and $15 \mathrm{pg} \mathrm{m}^{-3}(1,3-$ DNP). Tanabe $e t$ al. reported the following data ${ }^{9}$ by use of fluorescence detection; $0.3-8.7 \mathrm{pg} \mathrm{m}^{-3}$ (1,6-DNP),

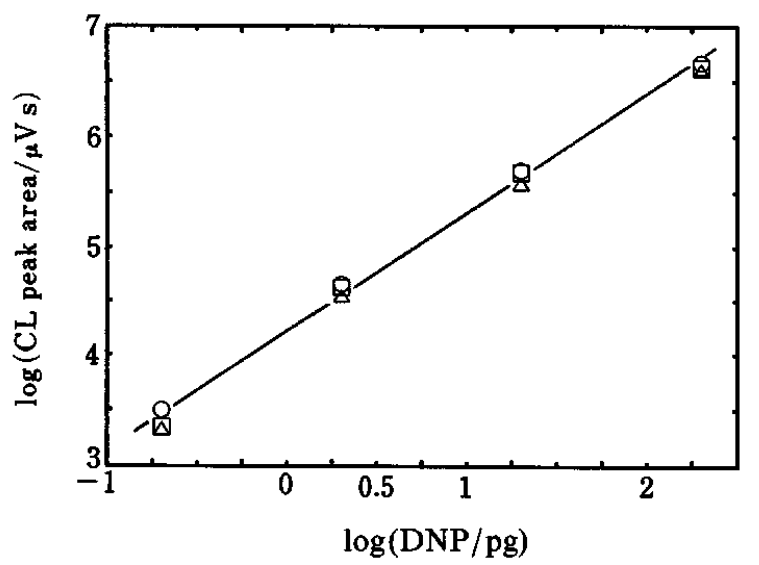

Fig. 6 Calibration curves for DNPs by the present HPLC-CL system. $O: 1,6-D N P, \triangle: 1,8-D N P$, and $\square: 1,3-D N P$. Conditions: TCPO/ $\mathrm{CH}_{3} \mathrm{CN}, 0.5 \mathrm{mmol} \mathrm{dm}^{-3} ; \mathrm{H}_{2} \mathrm{O}_{2} / \mathrm{CH}_{3} \mathrm{CN}$, $0.2 \mathrm{~mol} \mathrm{dm}^{-3}$; eluent, $\mathrm{CH}_{3} \mathrm{CN}-10 \mathrm{mmol} \mathrm{dm}^{-3}$ aqueous solution of imidazole ( $\mathrm{pH} 7.5)(1: 1)$; injection volume, $20 \mu \mathrm{l}$; column, 4.6 i.d. $\times 250 \mathrm{~mm}$ ODS.

Table 2 Detection limits of DNPs by the present method and conventional methods

\begin{tabular}{|c|c|c|c|c|c|}
\hline \multirow{2}{*}{ Method } & \multirow{2}{*}{$S / N$} & \multirow{2}{*}{ Injection volume $/ \mu \mathrm{l}$} & \multicolumn{3}{|c|}{ Detection limit/pg } \\
\hline & & & 1,3-DNP & 1,6-DNP & 1,8-DNP \\
\hline Present method & 4 & 20 & 0.05 & 0.025 & 0.025 \\
\hline CL method $6 \mathrm{a}$ & 3 & 20 & 0.07 & 0.7 & 0.10 \\
\hline Fluorescence method ${ }^{9}$ & 2 & 20 & 2 & 1 & 2 \\
\hline
\end{tabular}

a. The reported values for DAPs were converted to those for the corresponding DNPs. 
ND (not detected) - 6.6 $\mathrm{pg} \mathrm{m}^{-3}$ (1,8-DNP), and ND $4.7 \mathrm{pg} \mathrm{m}^{-3}$ (1,3-DNP) in Tokyo in 1986. The values obtained in Fukuoka seemed to be in the same order as those in Tokyo. The present off-line reduction-HPLC$\mathrm{CL}$ detection system will be a useful method for determination of trace DNPs in atmosphere.

The FIA by use of TCPO- $\mathrm{H}_{2} \mathrm{O}_{2}-\mathrm{CL}$ system was developed for the determination of PAH. After optimizing analytical conditions, the FIA was applied to determine PAH over a wide range of concentration with a small detection limit. On the basis of the FIA, the offline reduction-HPLC-CL detection system was developed for separation and determination of DNPs, which are the most mutagenic species among PAHs., ${ }^{1,7}$ The new techniques including metal-free system have successfully improved the sensitivity and the reproducibility of determination.

Financial support by a Grant-in-Aid for Scientic Research on Priority Areas (Formulation and Management of ManEnvironment System) from the Ministry of Education, Science and Culture of Japan is acknowleged.

\section{References}

1. M. L. Lee, M. V. Novotny and K. D. Bartle, "Analytical Chemistry of Polycyclic Aromatic Compounds", p. 50, Academic Press, New York, 1981.
2. J. Arey, B. Zielinska, W. P. Harger, R. Atkinson and A. M. Winer, Mutat. Res., 207, 45 (1988).

3. K. W. Sigvardson and J. W. Birks, Anal. Chem., 55, 432 (1983).

4. K. W. Sigvardson, J. M. Kennish and J. W. Birks, Anal. Chem., 55, 1096 (1984).

5. K. W. Sigvardson and J. W. Birks, J. Chromatogr., 316, 507 (1984).

6. K. Hayakawa, R. Kitamura, M. Butou, N. Imaizumi and M. Miyazaki, Anal. Sci., 7, 573 (1991).

7. H. S. Rosenkranz and R. Mermelstein, "Nitrated Polycyclic Aromatic Hydrocarbons", ed. C. M. White, p. 267, Huethig, Heidelberg, 1985.

8. M. Nagase, Y. Osaki, K. Hisatomi and T. Matsueda, "Kagaku Bussitsu Bunsekihou Kaihatsu Chousa Houkokusho (Research Reports on the Development of Analytical Methods for Chemical Substances, in Japanese)", p. 88, Japan Environment Agency, Tokyo, 1990.

9. K. Tanabe, H. Matsushita, C.-T. Kuo and S. Imamiya, $J$. Jpn. Soc. Air Pollut., 21, 5351 (1986).

10. E. S. Pysh and N. C. Yang, J. Am. Chem. Soc., 85, 2124 (1963).

11. K. Honda, K. Miyaguchi and K. Imai, Anal. Chim. Acta, 177, 111 (1984). 